\title{
CONTRIBUIÇÕES DE UM PROGRAMA DE EDUCAÇÃO A DISTÂNCIA SOBRE EDUCAÇÃO INCLUSIVA PARA A FORMAÇÃO CONTINUADA DO PROFESSOR EM INÍCIO DE CARREIRA
}

\section{CONTRIBUTIONS OF A DISTANCE EDUCATION PROGRAMME ABOUT INCLUSIVE EDUCATION TO THE CONTINUING EDUCATION OF BEGINNING TEACHERS}

\begin{abstract}
Ione Arsenio Silva*
Aline Reali ${ }^{\star *}$

Resumo: O período inicial de formação docente é insuficiente para oferecer todos os conhecimentos de que um professor necessita para o desenvolvimento de sua prática educativa. Nesse sentido, outros espaços e períodos de formação como a continuada são considerados como imprescindíveis para subsidiar o trabalho docente. Este artigo trata sobre um estudo que procurou oferecer contribuições na busca por novos espaços formativos na medida em que investigou a formação do professor dentro do contexto da EaD. A partir da seguinte questão de pesquisa: Quais os limites e possibilidades de um programa de formação continuada a distância via internet para professores dos anos iniciais do Ensino Fundamental? Conduzimos um estudo efetuado totalmente à distância em um ambiente telemático via Portal dos Professores (UFSCar) através da plataforma MOODLE, voltado para professores iniciantes. Adotando o modelo metodológico denominado construtivo - colaborativo, nossa investigação revelou, entre outros pontos, que o processo formativo investigado trouxe contribuições para os professores participantes da pesquisa - intervenção, oferecendo subsídios positivos para a sua prática pedagógica.
\end{abstract}

Palavras-chave: Professores iniciantes. Educação a distância. Formação de professores. Educação inclusiva.

\begin{abstract}
Initial teacher education is not enough for the provision of all the knowledge that teachers needs for the development of their educational practice. Thus, other formative spaces and times such as continuing education are considered essential to subsidy teachers practice. This article reports a study that aimed at offering contributions in the search of new formative spaces though the investigation of teachers in the context of Distance Education. The study started with the following research question: What are the limitations and possibilities of a distance continuing education via internet to teachers of the first years of Basic Education? A study was carried out at distance in a telematic learning environment via the Portal for Teachers (from the Federal University of São Carlos - UFSCar) through MOODLE platform, which is designed for beginning teachers. The investigation, which adopted a methodological model called constructive-collaborative, revealed among other issues that the formative process investigated contributed to the teachers involved in the research - intervention, offering positive subsidies for teachers' pedagogical practice.
\end{abstract}

Keywords: Beginning teachers. Distance education. Teacher education. Inclusive education.

\footnotetext{
* Doutora em Educação pela UFSCar. E-mail: <iar_senio@yahoo.com.br>.

* Doctor in Education from UFSCar. E-mail: <iar_senio@yahoo.com.br>.

** Doutora em Psicologia pela USP. Professora do Programa de Pós-Graduação em Educação da UFSCar. Secretária de Educação a Distância da UFSCar. E-mail: < alinereali@gmail.com>.

** Doctor in Psychology from UFSCar. Professor at the Post Graduate Programme in Education at UFSCar. Secretariat of Distance Education at UFSCar. E-mail: < alinereali@gmail.com>.
}

Olhar de professor, Ponta Grossa, 15(2): 285-296, 2012. Disponível em <http://www.uepg.br/olhardeprofessor> 


\section{Introdução}

O período de formação inicial docente, embora importante, apresenta limites como o fato de não ser capaz de propiciar o acesso a todos os conhecimentos de que um professor necessita para o desenvolvimento de sua prática pedagógica (GUARNIERI, 2005; MIZUKAMI et al., 2002). É comum o professor se deparar com dificuldades, mormente no início da docência, e constatar que não recebeu formação suficiente para enfrentá-las. Existirão sempre novos desafios pelos quais ele considerará insuficientes os saberes adquiridos durante os momentos formais de formação. Os estudos da área demonstram a fragilidade da ideia de um único período formativo ser capaz instrumentalizar um professor tornando-o apto para todas as situações vivenciadas no universo da escola.

Cada etapa ou ciclo da atividade docente, por exemplo, requer um tipo de conhecimento específico, já que as necessidades formativas de um professor em início de carreira diferem das necessidades de profissionais com mais de 10 anos de labor, que, por sua vez, diferem do que já atua nela há 20 anos. Todavia, de todas as etapas, a inicial se constitui na mais complexa da carreira do professor. Nono e Mizukami (2008) assinalam que os primeiros anos de magistério se constituem em etapa decisiva na estruturação da prática docente. Segundo as autoras:

[...] os primeiros anos da profissão representam um período intenso de aprendizagens e influenciam não apenas a permanência do professor na carreira, mas também o tipo de professor que o iniciante virá a ser. (NONO; MIZUKAMI, 2008, p. 2).

Para Marcelo Garcia (2009), os anos iniciais da docência são essenciais para "assegurar um professorado motivado, implicado e comprometido com a função" (p. 20).
É mister discutir ainda que inúmeras são as questões que fazem parte do universo escolar e, como consequência, do trabalho docente: prevenção de acidentes no trânsito, higiene e saúde, combate à violência, combate ao abuso de drogas, combate a epidemias etc. E isso sem contudo "perder de vista" a preocupação com os processos de ensino dos conteúdos curriculares. Acrescenta-se a essa situação o tipo de alunado cada vez mais heterogêneo que hoje requer que a escola reconheça e contemple os diferentes estilos e ritmos de aprendizagem provocados pela diversidade cultural, linguística, de aprendizagem, socioeconômica, entre outros. Esse contexto sobrecarrega o trabalho do professor podendo provocar uma grande carga de estresse e de desgaste, tanto físico quanto emocional, no tocante à tentativa de procurar responder a essas e outras demandas sociais com as quais convive cotidianamente nas instituições de ensino.

Nesse sentido, outros espaços e períodos de formação, como por exemplo a formação continuada, são considerados como imprescindíveis para subsidiar o trabalho docente, especialmente do principiante e principalmente hoje em que assistimos ao aumento nas atribuições dos professores e a consequente sobrecarga.

Este texto apresenta o recorte de um processo de pesquisa e intervenção que objetivou evidenciar

Quais os limites e possibilidades de um programa de formação continuada a distância via internet para professores dos anos iniciais do Ensino Fundamental?

Este estudo foi realizado totalmente a distância em um ambiente telemático via Portal dos Professores (UFSCar), através da plataforma MOODLE, e destinou-se aos professores em início de seu exercício profissional. O tema do processo formativo esteve relacionado à educação inclusiva. 
Acreditamos na relevância de temas que abordam questões envolvendo a educação inclusiva, porque partimos da premissa de que, no que tange ao ensino voltado para a diversidade do alunado, para o professor, devem ser disponibilizados programas formativos que abordem de maneira efetiva a questão de sua atuação junto a diferentes e variados grupos, quer nos aspectos sociais, étnicos e de aprendizagem. Os autores Diniz-Pereira e Zeichner (2008; 2005) asseveram que essa deve ser uma das preocupações dos programas de formação docente.

No processo de intervenção elaborado para a pesquisa, procuramos desenvolver com os participantes, de maneira processual e coletiva, atividades para serem realizadas em sala de aula. Elas foram construídas colaborativamente entre todos os envolvidos e procuraram estimular, através dos fóruns de discussão, das análises dos casos de ensino, da leitura de textos e outras atividades distribuídas ao longo da vigência do programa, que o professor buscasse e construísse conhecimentos a partir de sua prática, e que pudesse enxergar a escola como um espaço de formação profissional.

\section{Escola e formação continuada}

Com a noção da aprendizagem ao longo da carreira docente, a formação continuada voltada para o professor em exercício assume especial importância.

As práticas de formação continuada em nosso país são recentes. Elas já tiveram nomenclaturas como programa de reciclagem, capacitação, aperfeiçoamento ou mesmo formação. Gonçalves e Andrade (2007) ressaltam que tais práticas dificilmente atingem as expectativas esperadas, como a melhoria do trabalho docente, quando são organizadas em forma de palestras ou encontros de um ou dois dias, e ainda, quando não le- vam em consideração as necessidades pedagógicas dos professores, pois não se baseiam nas demandas das escolas.

Gonçalves e Andrade (2007) sinalizam sobre o reconhecimento cada vez maior da formação continuada como um importante aspecto para a melhoria educacional desde que os programas considerem as experiências e as situações de trabalho do professor. No entanto, as autoras alertam:

[...] a valorização das situações de trabalho e das experiências pessoais, assumem grande relevância para o crescimento profissional. Apesar do conhecimento construído pela experiência ser algo válido e determinante na construção do conhecimento profissional, sem uma análise disciplinada e organizada da própria experiência e da dos outros, o ensino pode transformar-se em rotina, com fracas oportunidades de aprendizagem e de desenvolvimento profissional, já que não se aprende pela experiência em si mesma, mas pela reflexão sobre a experiência. (GONÇALVES; ANDRADE, 2007, p. 458).

É preciso, portanto, que os programas de formação se voltem para a escola valorizando esse local como fonte de aprendizagem não somente para o futuro professor, como também para aquele que já exerce a profissão. Um professor aprende a partir de sua experiência, de sua prática e em contato com seus pares e não somente em momentos delimitados de formação. Estudos (COLE; KNOWLES, 2007; GUARNIERI, 2005; MIZUKAMI, 2007) evidenciam que é preciso atentar para a prática docente como também ser capaz de gerar conhecimentos. Eles salientam que tornar-se um professor, isto é, aprender a ser um professor, é um processo que se consolida na prática. É no exercício da profissão docente que se aprende a ensinar. Existe, portanto, uma parte da profissão que é aprendida durante os momentos de for-

Olhar de professor, Ponta Grossa, 15(2): 285-296, 2012. Disponível em <http://www.uepg.br/olhardeprofessor> 
mação e outra parte se consolida no próprio exercício da prática docente.

Os processos de aprender a ensinar e de aprender a profissão, ou seja, de aprender a ser professor, de aprender o trabalho docente, são processos de longa duração e sem um estágio final estabelecido a priori. Tais aprendizagens ocorrem, grande parte das vezes, nas situações complexas que constituem as aulas. (MIZUKAMI, 2007, p. 64).

A formação do professor é algo constante e a noção que se considera é a da aprendizagem docente ao longo da carreira, pois ela se constitui em um processo contínuo. Se existem, portanto, conhecimentos que são adquiridos no próprio exercício da prática educativa, é necessário, para tanto, a adoção de outros modos de socialização profissional e outras modalidades de formação que contemplem a escola e a reconheçam como um importante lócus de formação profissional. São conhecimentos nela construídos e nem sempre sistematizados, mas que influenciam na socialização profissional do professor. São os valores, modos de agir, condutas, representações, saberes produzidos na prática pedagógica.

Conforme destaca Sarti (2009, p. 134),

[...] a continuidade da formação docente implica considerar trajetórias, experiências e projetos relacionados ao ensino que são forjados e socializados no trabalho cotidiano dos professores.

A escola deve ser vista como o lugar onde a formação pode ser contextualizada e onde é possível articular a teoria e a prática. Assim, a escola não é apenas um local em que as crianças e jovens aprendem conteúdos e se desenvolvem. Ela é um espaço no qual os professores também realizam aprendizagens. Isto é, um espaço em que eles não somente ensinam, mas que também apren- dem. Aprendem sobre o exercício de sua profissão.

Nesse sentido, o contato com o local de desenvolvimento da função docente pode possibilitar a construção de conhecimentos somente possíveis de serem construídos a partir dessa aproximação com o cotidiano escolar. Sarti (2009) salienta que a estes conhecimentos, agregam-se os provenientes da história de vida, do contexto sociocultural, do ambiente familiar, além dos científicos e pedagógicos adquiridos nas instituições de Ensino Superior, o que demonstra a existência de uma multiplicidade de fontes das quais provém o saber do professor.

Em suma, os conhecimentos de um professor são decorrentes de sua experiência de vida, da etapa formal de formação e da atuação em uma classe junto aos alunos.

Este último dá um caráter peculiar à escola e, mais especificamente, à sala de aula, transformando-a em um local privilegiado de elaboração, construção e ampliação da aprendizagem do professor. É em sua ação pedagógica que um professor incorpora elementos que constituem a sua identidade profissional.

A identidade profissional é um processo evolutivo de interpretação e reinterpretação de experiências, uma noção que coincide com a ideia de que o desenvolvimento dos professores nunca para e é visto como uma aprendizagem ao longo da vida. Desse ponto de vista, a formação da identidade profissional não é a resposta à pergunta "quem sou eu neste momento?”, mas sim a resposta à pergunta “o que quero vir a ser?”. (MARCELO GARCIA, 2009, p. 2).

Durante o trabalho educativo, um professor é capaz de construir e reconstruir conhecimentos de acordo com a sua necessidade em utilizá-los. Nesse 
contexto, a prática pedagógica assume uma posição de relevância na formação do professor, já que ele é um profissional que constrói conhecimentos a partir dela. Não é interessante, portanto, diferenciar a sua formação da prática cotidiana nas escolas.

Dessa maneira, a noção simplista da função do professor, que a reduzia à aplicação de um conjunto de procedimentos e técnicas aprendidos exclusivamente em processos formativos específicos deve ser refutada, haja vista que para ensinar, não basta apenas conhecer a matéria. É imprescindível considerar aspectos da prática pedagógica na formação de um professor.

\section{A pesquisa}

Nosso estudo investigou a formação continuada do professor em início de carreira dentro do contexto da Educação a Distância $(\mathrm{EaD})$.

Nos últimos anos, a EaD foi a modalidade com mais impacto na área da formação docente, especialmente após a LDBEN 9394/96. Assim, presenciamos uma discussão cada vez mais intensa sobre a $\mathrm{EaD}$, principalmente nos meios acadêmicos devido ao seu grande crescimento e expansão impulsionada, em parte, pelo advento das novas tecnologias da informação, e também, pela implantação de um conjunto de políticas públicas de formação de professores por esta modalidade. Insta salientar que a $\mathrm{EaD}$ foi impulsionada com o advento da internet e do computador, haja vista que as possibilidades oferecidas por esses dois recursos no incremento das atividades pedagógicas são variadas. É possível criar links para esclarecer ou aprofundar um conceito tratado em um texto on-line, adicionar imagens, vídeos e sons, dinamizando dessa maneira o ensino e a aprendizagem.
O uso da internet também propicia formas mais interativas de aprendizagem com o uso adequado dos fóruns, chats e ferramentas de produção de texto coletivo.

Podemos dizer, portanto, que a grande revolução na Educação a Distância está ocorrendo no momento, através do uso da internet, pois temos em mãos uma tecnologia que permite que os conteúdos e as interações entre professor e aluno/ aluno e aluno ocorram em tempo real, em canais multidirecionais em que todos interagem e cada um contribui para a aprendizagem do outro. Professores e estudantes, assim, formam uma comunidade de aprendizagem. Esta também confere a oportunidade de usar as mais diferentes mídias como a escrita, a falada e a televisada. (MARINHO; SILVA, 2010, p. 6).

Tratou-se, portanto, de um processo de pesquisa e intervenção em que investigamos a EaD como espaço de formação docente e estudamos conjuntamente com um grupo de professores em exercício, práticas inclusivas em sala de aula construindo e discutindo ações pedagógicas que favorecessem a participação das crianças que apresentassem dificuldades de aprendizagem.

$\mathrm{O}$ processo ocorreu no segundo semestre do ano de 2009 e contou com a participação de 30 professores atuantes nos anos iniciais do Ensino Fundamental, residentes em diferentes estados brasileiros e todos cadastrados no Portal dos Professores/UFSCar. ${ }^{1}$ No escopo deste texto, os sujeitos da pesquisa foram identificados com as iniciais de professor-participante, isto é, como PP.

\footnotetext{
${ }^{1}$ O Portal dos Professores, localizado no seguinte endereço eletrônico (http://www.portaldosprofessores. ufscar.br), é um site que atua junto aos professores por meio da internet. Seu principal objetivo está no desenvolvimento de atividades e projetos que visam contemplar suas necessidades formativas dos profissionais da educação.
} 
Privilegiamos, no momento da seleção dos participantes, professores em início de carreira. Tal escolha se justifica por ser esse período permeado por dilemas e angústias, no qual os professores, ao se depararem com a realidade, muitas vezes colocam em dúvida se o que aprenderam enquanto ainda estudantes poderá auxiliá-los na prática. Segundo Flores (2009), assumir as responsabilidades inerentes ao ensino pode se converter em uma experiência dramática para o professor iniciante. São palavras desta autora (p. 69):

[...] em la mayor parte de los casos, aumenta la falta de apoyo y de ayuda a los nuevos professores por parte de sus colegas y el equipo de liderazgo de la escuela. Por el contrario, a veces se reservan para los professores em el inicio de la carrera las tareas más desagradables, los grupos más difíciles y los horários y las atividades menos deseadas. Sentimientos de aislamiento, de desilusión y hasta de frustración marcan, asimismo, la vida de muchos professores novatos cuando inician la docência [...].

Isto posto, o programa de formação continuada desenvolvido e denominado "A Diversidade na escola: refletindo sobre práticas inclusivas em sala de aula" foi dividido em etapas denominadas ciclos. Nesses ciclos, foram propostas leituras e discussões de textos, vídeos, slides, análise de casos de ensino, além de discussões no fórum e a elaboração em conjunto e colaborativamente de estratégias de ensino para serem desenvolvidas em sala de aula.

O intuito foi de que os professores-participantes, a partir da leitura dos textos disponibilizados no ambiente, das interações realizadas, com a pesquisadora, com os integrantes dos grupos e de suas experiências como professores, elaborassem estratégias de ensino a serem desenvolvidas junto aos alunos com dificuldades de aprendizagem que não os excluíssem do restante da turma. Para isso, tinham que levar em conta o tema de cada ciclo no planejamento e elaboração das ações pedagógicas. Os ciclos foram subdivididos em atividades com a duração de sete dias em média dependendo da proposta a ser realizada.

Buscamos desenvolver um processo formativo que pudesse oferecer subsídios aos professores na elaboração de práticas pedagógicas que envolvessem a modificação nas organizações de tempo, conteúdo, metodologia e estratégias avaliativas.

No estudo, utilizamos uma forma metodológica de pesquisa que privilegia a investigação colaborativa entre pesquisador e professores conforme explicitado a seguir.

\section{Metodologia}

Nossa investigação contemplou os propósitos da ação colaborativa a partir de um modelo de pesquisa e intervenção denominado construtivo-colaborativo. Esse modelo, apreendido dos pressupostos teóricos de Cole e Knowles (1993) e apresentado por Mizukami et al. (2002), permite o diálogo entre pesquisadores e professores, compreensões mútuas e ação comum.

Esse modelo de pesquisa e intervenção traz a crença de que o conhecimento

se constrói a partir de hipóteses que se estruturame se desestruturam. [...]Portanto é preciso intervir para desestruturar as certezas que desestruturam a prática. (MIZUKAMI et al., 2002, p. 43) .

O conhecimento docente é um processo em contínua construção e ocorre através de quebras de convicções e de certezas sobre a prática educativa. Todavia, este movimento, segundo o modelo construtivo-colaborativo, deve se dar de modo coletivo, na parceria entre pesquisadores e os sujeitos 
participantes da investigação, no exercício de ouvir o que o outro tem a dizer, na análise das posições individuais diferentes sobre determinado fenômeno.

Para Reali e Tancredi (2009), o modelo de pesquisa construtivo-colaborativo implica uma tendência para a inquirição, a qual objetiva gerar novos conhecimentos e contemplar problemas do dia a dia escolar.

De acordo com as autoras:

Nesse tipo de investigação, os pesquisadores sabem seu ponto de partida, mas não conhecem, de antemão, todos os caminhos que terão que percorrer nem qual será o ponto de chegada. Ficam o tempo todo numa situação oscilante, pois têm a prerrogativa de tomar as decisões, mas pretendem seguir as demandas do grupo participante. Também é imperativo que as especificidades dos papéis de cada grupo sejam respeitadas. Assim, ao adotar essa perspectiva de pesquisa, os pesquisadores passam a viver sobre 0 fio de uma navalha. (p. 4).

Adotamos no estudo as narrativas escritas efetuadas pelos professores-participantes do programa. A narrativa, portanto, foi também uma ferramenta metodológica.

Apontada por estudiosos (CUNHA, 2010 ; 1997) como um importante instrumento de auxílio à reflexão dos professores, a narrativa privilegia a transformação do professor de objeto a sujeito de sua formação. $\mathrm{O}$ uso da narrativa esteve em consonância com o nosso modelo teórico metodológico, pois ao registrar suas ações educativas junto aos alunos, as compreensões do programa, as dúvidas, os conhecimentos adquiridos, houve espaço para que os professores expusessem visões sobre o tema tratado, o conhecimento da prática que tinham, como também, a reflexão sobre cada etapa do programa oferecido. A narrativa, por ser um recurso que dá "voz" aos professores, se mostrou, conforme afirmado, um importante instrumento para este estudo.

Assim, acreditamos na proposta de investigações que tenham como intuito contribuir para com o desenvolvimento profissional de professores neste importante período do trabalho docente que é o período de inserção na profissão.

Durante o processo formativo, trabalhamos com as experiências de ensino e aprendizagem.

As experiências de ensino e aprendizagem se constituem em uma ferramenta que propicia, além do trabalho partilhado, o desenvolvimento de processos de reflexão sobre a ação, já que possibilita que os professores planejem, implementem e avaliem situações reais de ensino e aprendizagem. As experiências de ensino e aprendizagem favorecem a construção, de maneira conjunta e colaborativa, de procedimentos (a partir da teoria aliada à prática) a serem aplicados em sala de aula, bem como a avaliação dos resultados obtidos. Tal instrumento pode ser construído [...] "em processo, via negociação, assumindo múltiplas feições e dimensões temporais diversas" (MIZUKAMI et al., 2002, p. 164).

\section{Considerações}

Após a realização deste estudo, consideramos que a utilização da $\mathrm{EaD}$ via internet é um importante e interessante recurso formativo. No entanto, para que ela de fato seja um meio eficaz de formação, algumas precauções devem ser tomadas, já que existem alguns limites nessa via de estudo.

Primeiro, é preciso cuidado com a adoção de programas que preveem poucos momentos de interação entre o professor/ tutor e o aluno, limitando-os apenas a troca de mensagens eletrônicas (e-mails). 
Este modelo de programa exige um aluno autossuficiente, capaz de se organizar e de lidar com a flexibilidade que o estudo via web oferece (MORAN, 2009; MORETO, 2006). No caso dos participantes de nossa pesquisa, apreendemos que este foi o aspecto mais citado por eles como um elemento complicador. seguir:

Exemplifiquemos com a narrativa a

Já participei antes de um programa a distância. No início, senti muita dificuldade em me programar para acessar as tarefas e entregá-las nos prazos, acho que é mais difícil nesse sentido, porque quando frequentamos um programa todos os dias, nos programamos melhor, nos habituamos àquela rotina, e no programa on-line, temos a praticidade e a comodidade de estarmos em casa, por isso acabamos sempre deixando para depois, o que muitas vezes não dá certo. (PP1, 30/08/2009, relatório final).

Observamos, no decorrer do programa, outros episódios que evidenciaram essa dificuldade em organizar a formação on-line com as tarefas cotidianas.

Boa-noite, professora, por favor, a senhora poderia me enviar as atividades pendentes? Vou colocar em ordem nesta semana, pois tive fechamento de notas e relatórios para fechar e reunião de pais, reposição de aula, enfim, me passe, quero finalizar esta semana sem falta. Obrigada pela atenção. Um abraço. (PP9, 13/12/2009, correio interno).

As questões de autogoverno e de disciplina para estudos são muito exigidos quando se participa de um programa de EaD via internet, são habilidades imprescindíveis para que o aluno possa obter o melhor aproveitamento possível. Assim, é importante que os programas adotem ferramentas que propiciem momentos de interação entre os próprios participantes e entre estes e o professor ou tutor.

Outro aspecto a ser observado e que tem profunda relação com a qualidade do programa ofertado é o número de alunos por tutor, ou professor. De fato, um número elevado de participantes compromete os conhecimentos que por ventura poderiam ser adquiridos em um ambiente virtual, pois dificulta o acompanhamento da participação e das aprendizagens feitas pelos cursistas.

Observados tais aspectos, acreditamos na EaD via internet como um meio eficaz de formação profissional, primeiro por aproximar pessoas residentes em lugares distintos e distantes do local de formação, podendo realizá-la em horários que lhes são mais convenientes e possíveis. Segundo, que a web hoje oferece recursos capazes de romper com uma formação baseada na simples transmissão de conteúdo e com a ideia de aprendizagem passiva, oferecendo condições de interação entre professores-alunos e alunos-alunos. Esta interação com os pares, altamente facilitada por programas on-line, é apontada como uma dimensão relativamente nova (DIAS; LEITE, 2010) e que propicia a formação de grupos virtuais de trabalho e de aprendizagem.

Baseando-nos em alguns estudiosos (MIZUKAMI et al., 2002; COLE; KNOWLES, 2007; MIZUKAMI, 2007; GUARNIERI, 2005), procuramos construir um ambiente virtual de aprendizagem que propiciasse a interação e a colaboração entre os participantes. Mizukami (2007, p. 65) expõe a importância da colaboração entre os professores para o desenvolvimento profissional destes:

[...] salienta-se a importância da troca entre os pares, já que o magistério vem 
sendo analisado como uma profissão solitária e já que essa característica estaria sendo concebida como dificultadora não só do desenvolvimento profissional do professor, mas também da constituição de um corpo de conhecimentos próprios à profissão, atualmente inexistente.

Verificamos, ainda, que um programa desenvolvido a distância pode propiciar processos de construção coletiva de conhecimentos e, consequentemente, favorecer o desenvolvimento profissional de professores, conforme aponta a autora.

A EaD surge como um meio capaz de suprir esta carência de espaços formativos, especialmente a partir das facilidades oferecidas pelo aparato tecnológico como a computação em nuvem ${ }^{2}$ e as tecnologias móveis. É importante que se supere a visão que estabelece o confronto entre a Educação Presencial e a Educação a Distância, indicando-as como adversárias. É preciso, pois, que as reflexões estejam para além desse aspecto, conforme asseveram Dias e Leite (2010, p. 119):

Urge também refletir sobre que tipo de educação estamos construindo e queremos construir para os diversos níveis de ensino do nosso sistema, seja ela presencial ou a distância, mas uma educação que necessita ser ousada e que busque novos paradigmas $[\ldots]$

No que se refere ao tema do programa de intervenção, constatamos que houve ampliação no entendimento das participantes sobre educação inclusiva, conforme o excerto a seguir:

Em se tratando de inclusão escolar, notei, após a realização do programa, que os

\footnotetext{
${ }^{2}$ Segundo Taurion (2009), a expressão Computação em nuvem surgiu em 2006 e significa um modelo de computação que move todos os dados e aplicações dos usuários para grandes centros de armazenamento baseados na internet.
}

conhecimentos que eu tinha sobre o assunto eram o mínimo possível, porque em primeiro lugar, consegui entender que a Declaração de Salamanca aborda todos os tipos de inclusão escolar e que precisamos aprender mais sobre o assunto, creio que a falta de conhecimento sobre inclusão é um dos entraves para o seu desenvolvimento nas salas de aulas. (PP4, diário de bordo, 05/09/2009).

Frisamos a importância de se oferecer um apoio formativo aos professores iniciantes, principalmente em questões que envolvem a educação inclusiva. Posto que, conforme já apontamos, cada vez mais se reconhece que a formação do professor deve permitir o desenvolvimento de uma ação pedagógica que contemple os diferentes tipos de educandos, nos mais diversos níveis de ensino. Ou seja, uma "formação de acordo com os princípios de atenção à diversidade” (MARTINS, 2008, p. 140).

No entanto, há uma carência de espaços formativos que abordem os assuntos mencionados, bem como, outros importantes para a prática educativa, a EaD surge como um importante meio para minimizar esta problemática na formação do professor.

No que se relaciona à condição dos sujeitos de nossa pesquisa, professores iniciantes, embora a literatura da área aponte a importância dessa etapa da profissão docente, Flores (2009) observa que são escassas, especialmente por parte das políticas públicas, as iniciativas que visam oferecer suporte para aqueles que estão nessa etapa profissional. Nosso estudo indicou que um ambiente virtual de aprendizagem organizado para atender às demandas destes professores pode minimizar as angústias que os acometem nessa fase.

Considero a qualidade deste programa a distância muito melhor do que eu pensava, conheci pessoas interessantes 
de vários lugares, elas me ajudaram e muito a enfrentar as dificuldades que estava encontrando em minha sala, me deram dicas, sugestões e ideias de como trabalhar. Aprendi muito com o programa, pois é meu primeiro ano como professora. No final, conseguimos, montamos, a partir dos fóruns, várias sugestões de atividades que pretendo seguir durante o próximo ano. (PP3, 19/12/2009, relatório final).

A metodologia adotada se constituiu em uma importante estratégia tanto de investigação quanto de formação. O modelo construtivo-colaborativo, (REALI; TANCREDI, 2009), ao mesmo tempo em que objetiva gerar novos conhecimentos procura contemplar situações problemáticas do trabalho docente, especialmente por permitir o diálogo entre pesquisadores e professores e ações comuns em vários momentos do processo investigativo, conforme apontam Mizukami et al (2002).

Observemos outra narrativa:

Gostei muito da maneira como foi conduzido o programa, dos temas abordados, dos fóruns e das possibilidades de troca entre os participantes. Achei muito importante o acesso aos relatórios dos demais alunos sobre as experiências de ensino, pois foi enriquecedor poder observar as diferentes estratégias utilizadas pelos professores para propiciar a participação de todos os alunos no decorrer do desenvolvimento das atividades. (PP15, relatório final).

Consideramos que o processo formativo investigado trouxe contribuições para os professores participantes da pesquisa-intervenção, oferecendo subsídios positivos para a sua prática pedagógica, como novas estratégias metodológicas para a condução da ação educativa junto aos alunos. O modelo construtivo-colaborativo adotado se mostrou como um meio que favoreceu a aprendiza- gem dos participantes que puderam discutir, trocar experiências e elaborar colaborativamente ações pedagógicas, aliando os subsídios teóricos apresentados no programa com os advindos da prática, problematizando-a quando se fez necessário.

\section{Referências}

COLE, A.; KNOWLES, G. Teacher education: Toward an inquiry orientation. In: REALI, A.; MIZUKAMI, M. (Orgs.) Formação de professores: tendências atuais. São Carlos: EDUFSCar, 2007.

- Teacher development partnership research: a focus on methods and issues. American Educational Research Journal, v.3, n.30, p. 473-495, 1993.

CUNHA, M.; ZANCHET, B. A problemática dos professores iniciantes: tendência e prática investigativa no espaço universitário. Educação, Porto Alegre, v. 33, n. 3, p. 189197, set./dez. 2010.

CUNHA, R. Pesquisa narrativa: uma estratégia investigativa sobre o ser professor. $5^{\circ}$. Encontro de Pesquisa em Educação da UFPI. Anais...Teresina: Edufpi, 2009, p-01-12. Disponível em: <www.ufpi.br/ subsiteFiles/.../35_Renata\%20Cristina\%20 da\%20Cunha.pdf.>. Acesso em: 05 jun. 2010.

CUNHA, M. Conta-me agora!: as narrativas como alternativas pedagógicas na pesquisa e no ensino. São Paulo, Revista Faculdade de Educação, v. 23, n. 1-2; jan./dez, 1997.

DIAS, R.; LEITE, L. Educação a distância: da legislação ao pedagógico. Petrópolis: Vozes, 2010.

DINIZ-PEREIRA, J.; ZEICHNER, K. Justiça social: desafio para a formação de professores. Belo Horizonte: Autêntica, 2008. 
DINIZ-PEREIRA, J.; ZEICHNER, K. Pesquisa de educadores e formação docente voltada para a transformação social. Cadernos de Pesquisa, São Paulo, v. 35, n. 125, p. 63-80, maio/ago. 2005.

FLORES, M. La investigación sobre los primeros años de ensenãnza: lecturas e implicaciones. MARCELO GARCIA, C. (Org.). El profesorado principiante: inserción a la docência. Octaedro: Barcelona, 2009, pp. 59-98.

GUARNIERI, R. Aprendendo a ensinar: o caminho nada suave da docência. Autores Associados, São Paulo, 2005.

GONÇALVES, M.; ANDRADE, A. Disponibilidade e autoaplicação: desenvolvimento profissional e plurilinguismo. Revista eletrônica PUCRS, Porto Alegre/RS, vol. 30, n.3, p. 457-477, dez. 2007.

NONO, M; MIZUKAMI, M. Processos de formação de professoras iniciantes. Revista Brasileira de Estudos Pedagógicos, Brasília, v. 87, n. 217, p. 382-400, set./dez. 2006.

MARCELO GARCIA, C. Políticas de inserción a la docência: de eslabón perdido a puente para el desarrollo profesional docente. In. (Org.). El profesorado principiante: inserción a la docência. Octaedro: Barcelona, 2009, pp. 7-58.

MARINHO, C.; SILVA, A. Educação a distância: estudo da gestão do EaD IMIP. $4^{\circ}$. Encontro de Ensino Pesquisa e Extensão das faculdades SENAC. Anais... Pernambuco: Editora SENAC, 2010, p. 1-8. Disponível em: <http://www.pe.senac.br/ascom/ faculdade/Anais>. Acesso em: 01 dez. 2010.

MARTINS, H. G.; GALDINO, M. N. D. Ensino a distância: entre a institucionalidade e a formação de uma nova cultura. $29^{\mathrm{a}}$
Reunião Anual da ANPED. Anais... Caxambu, 2006. Disponível em: <http:// www.anped.org.br/reunioes/29ra/trabalhos/ trabalho/GT16-2588--Int.pdf>. Acesso em: 20 dez. 2009.

MIZUKAMI, M. etal. Escolaeaprendizagem da docência: processos de investigação e formação. São Carlos: EdUFSCar, 2002.

MORAN, J. Novos caminhos do ensino a distância. CEAD - Centro de Educação a Distância. SENAI, Rio de Janeiro, ano 1, n.5, out/dez. 1994, p. 1-3. Disponível em: $<$ http://www.eca.usp.br/prof/moran/dist. htm>. Acesso em: 13 abr. 2009.

MORETO, C. Parceria no engendramento de uma educação sem distâncias: a experiência da UFES no programa de Pedagogia/EAD. 29a Reunião Anual da ANPED. Anais... Caxambu, 2006.

REALI, A.; TANCREDI, R. A importância do que se aprende na escola: a parceria escola- famílias em perspectiva. Paidéia, Ribeirão Preto/SP, vol.15, n.31, p. 239-247. Disponível em: <http://sites.ffclrp.usp.br/ paideia/artigos/31/10.htm\#_ftn2>. Acesso em: 18 ago. 2009.

SARTI, F. Parceria intergeracional e formação docente. Educação em Revista, Belo Horizonte, v.25, p. 133-152, ago. 2009.

TAURION, C. Cloud computing: computação em nuvem: transformando o mundo da tecnologia. Rio de Janeiro: Brasport, 2009.

Enviado em: 30/09/2012.

Aceito em: 13/12/2012 